\title{
Strengths-Based Nursing: A Process for Implementing a Philosophy Into Practice
}

\author{
Laurie N. Gottlieb, RN, PhD ${ }^{1,2,3}$ \\ and Bruce Gottlieb, PhD 1,2,3
}

\begin{abstract}
Strengths-based nursing (SBN) is both a philosophy and value-driven approach that can guide clinicians, educators, manager/leaders, and researchers. SBN is rooted in principles of person/family centered care, empowerment, relational care, and innate health and healing. SBN is family nursing yet not all family nursing models are strengths-based. The challenge is how to translate a philosophy to change practice. In this article, we describe a process of implementation that has organically evolved of a multi-layered and multi-pronged approach that involves patients and families, clinicians, educators, leaders, managers, researchers as well as key stakeholders including union leaders, opinion leaders, and policy makers from both nursing and other disciplines. There are two phases to the implementation process, namely, Phase I: pre-commitment/pre-adoption and Phase 2: adoption. Each phase consists of distinct steps with accompanying strategies. These phases occur both sequentially and concurrently. Facilitating factors that enable the implementation process include values which align, readiness to accept SBN, curiosity-courage-commitment on the part of early adopters, a critical mass of early adopters, and making SBN approach both relevant and context specific.
\end{abstract}

\section{Keywords}

strengths-based nursing, strengths-based leadership, strengths-based care, implementation, leadership and management training program

1. McGill University, Montreal, Quebec, Canada

2. Jewish General Hospital, Montreal, Quebec, Canada

3. International Institute of Strengths-Based Nursing and Health Care, Montreal, Quebec, Canada

Corresponding Author:

Laurie N. Gottlieb, Ingram School of Nursing, McGill University, 680 Rue Sherbrooke West, Montreal, Quebec, Canada H3A 0B8.

Email: laurie.gottlieb@mcgill.ca 
Almost 40 years ago, the first author wrote a paper for a graduate seminar on the problems with the health care system. In the paper she wrote that the health care system of the 1970s was fragmented, depersonalized, deficit-based and diseasecentric and in effect, was a misnomer as the health care system was neither healthfocused nor caring. Fast forward to 2017 and many of the same criticisms continue to be leveled at health care systems in the United States (Chokshi, Chang, \& Wilson, 2016), Canada (Naylor et al., 2015), and other Western countries (lacobucci, 2017). While many solutions have been advanced over the years as evidenced by the multiple attempts at re-engineering and restructuring the health care system (Mintzberg, 2012), the system has remained fundamentally the same. Despite the success of scientific medicine, a negative aspect has been the systematic exclusion of the patient and family social lifeworlds despite ongoing attempts to add human concerns related to patient and illness experiences in health care ( $P$. Benner, personal communication, October 2015). These attempts have included commitments by many health care institutions subscribing to ideals such as Person/Family Centered Care (PFCC; Morgan \& Yoder, 2012); Patient Engagement (Carman et al., 2013); Patient Experience (Manary, Boulding, Staelin, \& Glickman, 2013); Patient Empowerment (Rodwell, 1996); Whole Person Care (Thornton, 2005); and Collaborative Partnership (Gottlieb \& Feeley, 2005). Yet these ideals have remained primarily rhetoric and have had limited success in becoming the new reality in practice (Naylor et al., 2015).

If we take a step back and look at what has happened to nurses and nursing during these intervening 40 years, the picture is mixed. On the "gain" side, we have a more educated workforce. In many regions of the country and the world, entry to practice is at a baccalaureate level and we have a critical mass of master and doctoral prepared nurses performing a wide range of roles. Many have greater control and more autonomy over their practices. A handful of nurses have even broken through the glass ceiling as evidenced by the recent appointment of Rear Admiral Sylvia Trent-Adams, the first nurse to be appointed Surgeon General of the United States, and some nurses have found their way to national and international decision-making tables.

However, the losses have far outweighed the gains. Over these past four decades, nurses' power within the system has been systematically eroded (Shariff, 2014). Consider the move to de-skill and replace expert, knowledgeable nurses with less educated, less skilled, less experienced individuals (Registered Nursing Association of Ontario, 2016). Consider the loss of control nurses have experienced over their time spent with patients and families, time that might have been spent providing the fundamentals of care (Kitson, Conroy, Wengstrom, ProfettoMcGrath, \& Robertson-Malt, 2010). Consider how nursing budgets have been drastically cut and nursing leaders and managers have been replaced by non-nurses to make decision about nursing to meet "bottom lines" with less regard to the effects on patient and family care (Griffiths, Ball, Murrells, Jones, \& Rafferty, 2016). Consider how nurses have developed new roles to meet the new realities of health care yet many of these roles have expanded into medical roles and nurses have assumed more medical tasks at the expense of nursing care (Kooienga \& Wilkinson, 
2017). Finally, consider how nursing's voice is barely heard as few nurses are at decision-making tables where policies are made (J. Shamian, President of ICN, closing address, 3rd Commonwealth Nurses and Midwifery Conference. March 1213, 2016, London, England).

Part of these losses can be explained by the erosion and dismantling of nursing leadership positions at all levels of the organization from Directors of Nursing to unit and clinical managers (Hughes, Carryer, \& White, 2015). This dismantling has taken place despite solid empirical evidence that quality patient family care is directly related to quality nursing leadership (Tomey, 2008).

All these changes have had a devastating effect on the nursing workforce altering nurses' workplace environments and impacting nurses personally and professionally and affecting the quality of nursing care provided to patients and their families (Kutney-Lee, Wu, Sloane, \& Aiken, 2013). Research has found that nurses suffer from burnout, experience a high incidence of mental and physical problems, and high absenteeism rates (Read \& Laschinger, 2015). Nurses are frustrated and fed-up, feel that their knowledge and skills go unrecognized, and are underutilized as they are unable to practice to the full scope of their education and competencies (The National Academies of Sciences, Engineering, Medicine, 2010). Nurses report that dissatisfaction with the work environments is sufficient to make them want to leave nursing altogether (Peckham, 2015).

Many believe that we are on the cusp of ushering a third era in health care that will focus on the rewriting of the social covenant with health care professionals. This new era is a reaction to the second era in health care, beginning in the 1980s, whose focus has been on accountability, scrutiny, measurements, incentives, and markets (Berwick, 2016). What Berwick (2016) envisions in this third era is some major shifts on the part of doctors - shifts from lack of respect, distrust, and disengagement to a return to respect, trust, civility, and a protection of moral values; from a preoccupation with quantity (efficiency) to one that also includes quality care (effectiveness); from being a market-driven health care system to a consumer/user/patient-driven system; from rigid roles to roles assigned based on knowledge, skills, and outcomes; and from a measurement only focus system to one that also includes strategies for making improvements.

Bringing forth a new era in health care will not just require a new covenant between society and health care professionals but also an expansion of paradigms to guide them. While the Medical Model, a deficit-based, disease-centric model, is essential for diagnosis and treatment, what is also needed is a "Strengths-Based" paradigm to promote person and family health, facilitate healing, and alleviate suffering. This is the work of nurses; this is the essence of nursing (Gottlieb, 2013).

Reclaiming the essence of nursing through Strengths-Based Nursing (SBN) can change nursing and in so doing, create a health care system that embodies both health and care. However, to achieve this vision requires creating more than one future (Wallach, 2017). In this article, we describe how we are creating a different future through SBN. We describe a multi-layered, multi-pronged strategies that we are using to implement SBN in transforming both the health care and educational 
systems. But first we begin with a brief overview of SBN and why it is ideally suited to usher in this new era of health care and reclaim the essence of nursing.

\section{SBN: What It Is, and SBN's Relationship to Family Nursing}

SBN is family nursing, but not all family nursing is strengths-based as is the case when nurses focus almost exclusively on problems and deficits rather than the whole; when nurses believe that their role is to "fix" problems by telling families what to do; and when nurses expect patients and families to comply with the plan they have devised (for a comparison between a Strengths-Based approach and a traditional, hierarchical, deficit-based model see Gottlieb, 2013). There has been a growing interest in working with family strengths (Feeley \& Gottlieb, 2000). In fact, focusing on family strengths is one of the five core family competencies identified by the International Family Nursing Association (IFNA; 2015) Position Statement on Generalist Competencies for Family Nursing Practice. However, what is unclear is why nurses should be concerned with working with individual and family strengths and how nurses could work with family strengths to achieve family goals. Moreover, the connection between strengths and IFNA's focus, namely, to support family and individual growth; the improvement of self-management-abilities; the facilitation of successful life transitions; the improvement and management of health; and the mobilization of family resources, has yet to be made explicit.

SBN goes beyond a focus on strengths, although uncovering, discovering, and developing strengths are integral to SBN.

SBN is not a model but rather is a philosophy of nursing and a value-driven approach that is used to guide clinicians (Gottlieb, 2013, 2014), educators (Gottlieb \& Benner, 2013), and leaders/managers (Gottlieb, Gottlieb, \& Shamian, 2012).

As a philosophy of nursing, SBN expands the nurses' imaginary horizons that reflect a way of being and influences and shapes how nurses create healthpromoting and healing environments for persons/patients and families; how educators create healthy learning environments for learners; and how clinical leaders and managers create healthy workplace environments for their staff.

SBN has its foundational roots in Florence Nightingale's approach to nursing (Nightingale, 1860); the McGill Model of Nursing (Gottlieb \& Rowat, 1987); principles of person/family centered care (PFCC); Gooding et al., 2011); empowerment and developing agency (Gibson, 1991; Regan \& Rodriquez, 2011); relational care (Koloroutis, 2004); and innate and acquired capacities for health and mechanisms of healing (Gottlieb \& Ponzoni, 2016). These foundations are operationalized through eight strengths-based values, namely, health and healing, uniqueness, holism and embodiment, subjective reality/created meaning, personenvironment integral, self-determination, learning-readiness-timing, and collaborative partnership (for the definition of these values, see Figure 1). Values guide what to observe for, attune and attend to, and ask about. Values serve to determine what is salient and relevant as values guide decisions and then, actions. 
Figure I. SBN value wheel and definitions.

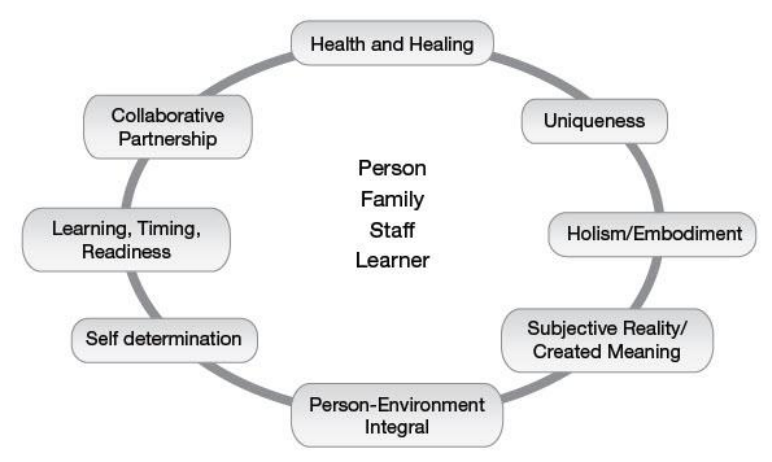

Health and Healing: Health and healing are about wholeness. Health is about becoming by developing capacities, capabilities and skills to maximize functioning, adaptable and flexible in responding to challenges. Healing is about repairing, renewing, restoring and arriving at new levels of wholeness

Uniqueness: Uniqueness defines the person/family/organization specialnesswho and what they are and what they strive to be. Uniqueness is reflected in their assets, capabilities, capacities, competencies, potentials, skills, and talents i.e., their strengths.

Holism/Embodiment: Holism recognizes the interconnectedness between and among parts. Parts are best understood in relation to each other and to the whole. The parts and whole vary taking their definition from the context and becoming the context. Embodiment is the integration of mind-body. Embodiment also represents and reflects what is important.

Subjective reality/created meaning: SR/CM recognizes that everyone lives and experiences reality in their own unique ways. To make sense of, understand, and explain reality, person/family create meaning through having purpose, developing narratives, and connecting to others.

Person/ environment integral: Person/family/organizations are situated in many environments: physical (space, time), relational (connections), social (political, economic). The person/family/environment influences and are influenced by their different environments The family can be both the person as well as the environment depending of the context and circumstance.

Self determination: SD involves choice, choosing, control, and agency. SD involves developing and exercising agency through taking charge, exercising and being involved in making decisions.

Learning/timing/readiness: Learning is required for survival, change, and growth and involves the acquisition of knowledge, skills; readiness is a prerequisite for learning; timing involves coordinating actions to achieve the best results.

Collaborative partnership: $\mathrm{CP}$ is about power; how it is distributed and shared to give person/family/organization voice to enable them to achieve their goals, their vision.

Note. $\mathrm{SBN}$ = strengths-based nursing; $\mathrm{SR} / \mathrm{CM}=$ subjective reality/created meaning; $\mathrm{SD}=$ self-determination; $\mathrm{CP}=$ collaborative partnership.

SBN is part of a growing movement within and across disciplines and professions. For example, SBN shares many of the same principles that underpin Positive Psychology (Seligman \& Csikszentmihalyi, 2000); Asset Approach (Law; Carter \& Barrett, 2006); Capability Approach (Economics; Nussbaum, 2011; Sen, 1999); Recovery Model (Mental Health and Rehabilitation; Jacob, 2015); and Solution-Focused Approach (Occupational Therapy; Cockburn, Thomas, \& Cockburn, 1997). These models and theories provide an alternative worldview from the problem-based, deficit-based models to meet a specific profession's social mandate. Thus, how a strengths approach is expressed varies from one discipline to the next. However, there are important advantages when professionals subscribe to a common set of foundational principles; it can facilitate dialogue between disciplines and professionals, enhance understanding, and open up opportunities for greater interdisciplinary exchange and interprofessional collaboration. Table 1 summaries some of the key features of SBN.

\section{Table I. Key Features of SBN.}

- SBN appreciates that humans are wired for strengths and organizations have inherent strengths. Strengths are required for survival, growth, development, thriving, relating.

- SBN is about discovering, uncovering, developing, and amplifying strengths (i.e., capacities, capabilities, competencies, skills, gifts, talents). 
- SBN is about creating health-promoting and when needed, healing environments.

- SBN is about seeing, understanding, and appreciating the whole person, the whole family, the whole unit, the whole organization - identifying and developing their inner spirit, resiliency, courage.

- SBN situates the person, the family, the unit, the organization in context and appreciates interconnections between and among parts.

- SBN asks about individuals, family, units, and organizations: What does X do best? What is functioning well here? What supports are needed to bring out the best, to optimize functioning, to turn things around?

- SBN asks: How do I leverage strengths to minimize, contain, circumvent that which is not working, work around obstacles, and, or strengthen that which is working?

- SBN observes and asks: Which strengths (capacities, capabilities, competeicies, skills) are working well? Which ones need to be supported or strengthened and which new ones need to be developed?

- SBN views challenges not as roadblocks but as opportunities for growth.

- SBN amplifies positive experiences and emotions while soothing, reducing negatives or those that might sabotage.

- A strengths approach looks for possibilities and knows that there are many routes to achieving a goal, bringing the future closer, and realizing a vision.

Note. SBN = Strengths-Based Nursing.

\section{Changing Nursing Practice}

We return to the difficulties of bringing about significant changes to nursing practice and the health care system. The gap between both nursing and medical science and practice and between education and practice has been disappointing, as most of the remedies tried, from continuing education to evidence-based practices, have met with limited success (Agency for Healthcare Research Policy, 2006).

During the 1980s, the gap between theory and practice had widened and many models were developed to help narrow this gap (Rogers, 2003). Early focus was on dissemination with far less attention paid to implementation and its uptake. For many, dissemination was an end rather than a means to an end (Green, Ottoson, Garcia, \& Hiatt, 2009). It was assumed that awareness and knowledge would automatically be followed by changes in practices as reflected in the adoption of a new set of attitudes and behaviors,. Implementation is in fact a distinct process that normally requires adapting or even reframing the theory or research that is being introduced to make it more compatible to the organizational context (Green et al., 2009). To quote Leonardo da Vinci, "knowing is not enough we must apply" (Suh, 2005).

A proposal by the National Council Institute of Canada's Joint Working Group on Translational Research and Knowledge Integration found that the products of research have to be integrated across multiple levels and sectors of health systems in which they would be applied (Best, Hiatt, \& Norman, 2008). It appears that while 
policy is almost always made at a central level, implementation is normally at a local level. Thus, the importance of leadership in implementing strategic change in a health care system cannot be underestimated (Caldwell, Chatman, O'Reilly, Ormiston, \& Lapiz, 2008). A number of approaches have been proposed to enhance implementation science including applying best principles of system science using a modeling process (Northridge \& Metcalf, 2016). However, a scan of the literature indicates that large-scale initiatives to improve health care tend to be fragmented from an implementation standpoint (Perla, Bradbury, \& Gunther-Murphy, 2013). What has met with more success has been the application of specific knowledge translation and uptake theories (Easterbrooks, Thompson, Lovely, \& Hofmeyer, 2006) applied to best practice diffusion (Dearing et al., 2017) in an effort to close the evidence-to-practice gap (Lang, Wyer, \& Haynes, 2007). However, these knowledge translation and uptake initiatives have all had the goal of changing a specific health care procedure or practice. They have not been directed at changing the approach to practice of a profession, in our case, nursing.

Over the course of 3 years, a strategy for implementation of SBN has slowly evolved. We did not set out to develop an overall implementation strategy but one has organically emerged that is directing our current and future efforts. It is a multileveled, multi-pronged approach that involves clinicians, educators, leaders, managers, researchers, opinion leaders, and policy makers from both nursing and other disciplines. It includes key stakeholders who have the power to bring about change. It involves the practice settings, educational and workplace sectors, and extends to governance bodies that are responsible for creating change through evidence-based policy. We have identified a process of implementation (Figure 2) with distinct steps with their associated strategies that can occur both sequentially and concurrently.

Figure 2. Process of implementation.

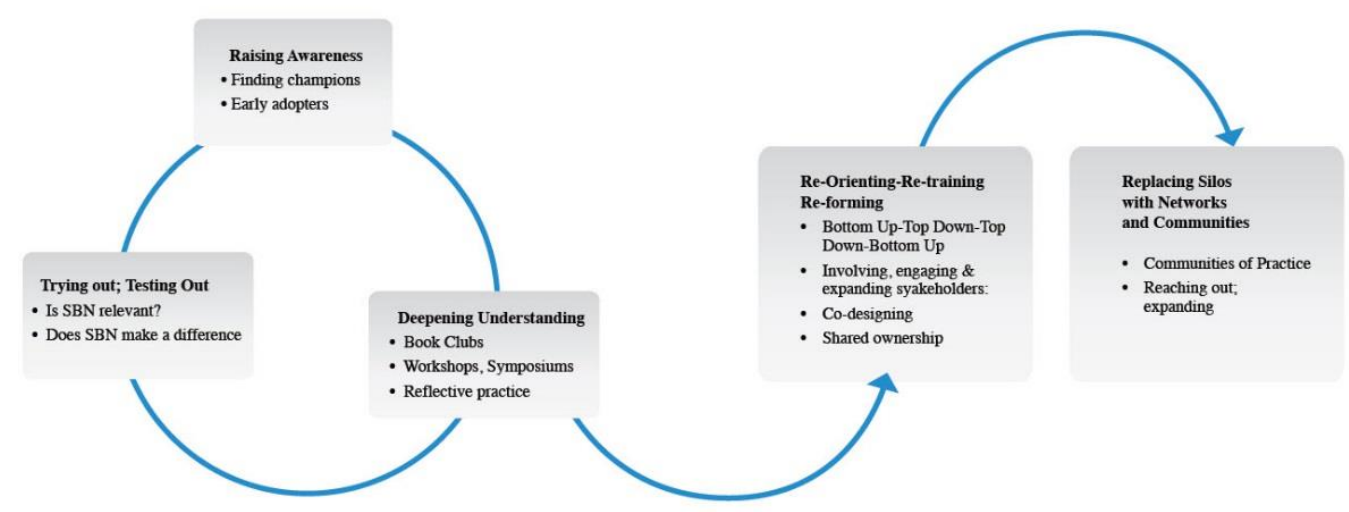

Phase 1: Pre-commitment-Pre-adoption

Phase 2: Adoption 


\section{Phase I: Pre-Commitment/Pre-Adoption}

The Pre-Commitment/Pre-Adoption Phase consists of three steps, namely Raising Awareness, Deepening Understanding, and Trying On: Testing Out which are iterative, each shaping and being shaped by the other steps.

\section{Raising Awareness}

The first step is to raise awareness of a new paradigm, new idea, or new approach. Raising awareness is traditionally accomplished through dissemination networks in the forms of publications, social media, digital materials, word-ofmouth, and the like. However, what gives a new paradigm, a new idea, or a new approach its momentum is having champions and early adopters (Shaw et al., 2012).

Champions are those individuals who have a platform and voice. They are opinion makers and opinion shapers. They have the power to shape and influence the conversation.

When the first author's book, Strengths-Based Nursing Care: Health and Healing for Person and Family was published in 2013, we were fortunate to have early champions who recognized that SBN could be a game changer with the potential to transform nursing and the health care system. These champions came from all levels and all sectors including influential thinkers, journal editors, and nursing leaders in the educational and practice sectors. One of our champions immediately saw the potential of SBN and used her influence to raise awareness of SBN. She used her position of influence to not only make others aware of SBN but explained how SBN could address some of their concerns and the chronic problems that had yet to find solutions. She organized meetings and brought together leaders in the field who were in positions to introduce SBN into their workplaces. From these contacts and connections, individuals came forth who were intrigued by SBN's potential and who wanted to learn more. These individuals became our early adopters. As Berwick (2003) noted, what characterizes early adopters is their openness to finding new ideas to try out.

\section{Deepening Understanding}

Early champions and adopters wanted to learn more. Learning about SBN took many different forms. For example, some organized book clubs of 10 to 20 individuals from different units in their hospital who dedicated time to studying the book Strengths-Based Nursing Care (Gottlieb, 2013). In one hospital, those who attended were middle management, clinical nurse specialists, and nurse educators. In another institution, book clubs included point-of-care nurses and in educational institutions, they included faculty. What was common to all the book clubs was that attendance was voluntary. Learners identified core ideas and messages in each chapter that had resonated with them, shared stories that linked these ideas to their own practice or experiences, and debated and discussed the core messages in each chapter. Those leaders who not only encouraged their staff to attend the book 
club but who also attended and actively participated themselves, sent a powerful message to all of their commitment to SBN.

Other forums for deepening understanding of SBN were through workshops and conferences. It is not surprising that two of the leaders and their management teams who hosted and attended the book clubs also were key players in organizing a symposium to explore issues of creating and sustaining SBN in the workplace.

Other follow-up activities included creating reflective practice groups (Gustafsson, Asp, \& Fagerberg, 2007). In one hospital, a group of advanced practice oncology nurses volunteered to be part of a bi-monthly book club on SBN, and when the book club concluded 5 months later, they decided to continue to deepen their understanding of SBN. They met bi-monthly engaging in reflective practice sessions. In the process of discussing, sharing stories, critically reflecting on their own and on their colleagues nursing with patients and families, and by examining one SBN value at a time, they began to uncover elements of SBN in their own practice and to make explicit and visible their nursing, first to themselves, then to other nurses, and finally to their colleagues on the interdisciplinary team. They began to document their nursing guided by SBN values and language. SBN had provided them with the framework and the language to communicate their nursing to others.

\section{Trying On: Testing Out}

Often nurses when they hear of a new theory, philosophy, or approach may like the ideas but will dismiss or discount them. There may be many reasons but an often-voiced reason is, "sounds interesting but impractical and does not fit the real world of practice" or, "this takes time and who has the time to sit and talk with patients and families?" What these nurses fail to understand is that SBN is a mindset, a way of being and once embraced and integrated, becomes the lens for viewing and understanding their patients' and families' lifeworlds. It becomes an integral part of what they listen for, attune to, attend to, and then, how they respond.

Some nurses, before fully embracing and committing to SBN, want to try on and test out some of SBN's core features. They want to discover and experience firsthand, "Is SBN relevant to my role? to my situation?" "Does SBN make a difference?" It was by experiencing firsthand the impact that an SBN approach had on patients and families that clinicians and teachers decided to commit. To illustrate, a point-of-care nurse, Jenette Schoon, who worked in a long-term children's rehabilitation hospital had been unhappy with the way family discharge planning meetings has been conducted. Jenette felt that the team focused on family problems, deficits, and family weaknesses and did not pay sufficient attention to their strengths. Moreover, families were given a discharge plan from the team in which they had had little to no input. After reading Strengths-Based Nursing Care, she believed that the team could conduct these family meetings in a different way. She discussed using a strengths approach with the team and they decided to try it out. The response from families was overwhelming positive. This 
was the evidence that she needed to begin her own journey to learn more about SBN and to become a driving force in bringing SBN to her hospital.

Other nurses have tried out SBN, using the value wheel to guide their nursing and discovered how SBN transformed their nursing (Figure 1). Renata Benc, an Advanced Practice Oncology Nurse, explained "It reminds me of the essence of nursing: being present with patients and families, understanding their reality, and empowering them to achieve a new normal."

Christina MacDonald, a colleague of Renata, elaborated: "SBN reminded me of why I am a nurse, to be there for my patient and families and not just do what the medical team says needs to be done ... there is no better satisfaction than advocating for your patient and family and being heard".

Another colleague, Nancy Drummond described SBN's benefits for her and how SBN provides a different lens to see patients and families, "The surest protection from compassion fatigue is to use a SBN approach. I work in cancer care and all that I can see is health, wholeness, growth and the infinite potential of the human spirit!"

\section{Phase 2: Adoption}

\section{Re-Orienting, Re-Training, Re-Forming}

An important touchpoint of implementation involves engaging and expanding stakeholders at all levels within an organization and then, between organizations. Stakeholders include the direct providers of care and those who indirectly influence care, such as middle managers and clinical leaders, who are in supervisory or educational roles. It also extends to the leaders who are responsible for developing and creating policy and ensuring policy filters down to all levels care (Tornabeni \& Miller, 2008). This Bottom-Up-Top-Down-Top-Down-Bottom Up approach (Mukamel, Haeder, \& Weimer, 2014) is a critical ingredient for success because all levels of nurses need to be involved and engaged in adopting this approach and then tailoring SBN to fit their particular context.

This approach was taken when the faculty of the Ingram School of Nursing (ISoN) at McGill University in Canada voted to adopt SBN as the philosophy to underpin both its undergraduate and graduate curricula. After a lengthy period of study, debate, and discussion, the faculty voted to move in this direction. Once the faculty had made its decision, the Director of the ISoN along with the Directors of both the undergraduate and graduate programs put in place the resources including access to experts to help faculty revise the curriculum of all their programs, develop the content for individual courses that integrate SBN's philosophy, principles, values and pragmatics, create on-line modules to orient preceptors in SBN, and new pedagogical approaches to develop knowledge as well as skills of clinical reasoning required for clinical judgment and clinical decision making.

Another important touchpoint of implementation of SBN in the workplace has been to develop an educational program to re-train clinical managers and leaders in Strengths-Based leadership principles (Gottlieb et al., 2012). The rationale for targeting unit managers and clinical leaders who directly supervise point-of-care nurses is because they are major influencers in shaping the quality of nurses' work 
environments (Birken, Lee, \& Weiner, 2012). We believe that when managers create healthy workplace environments, understand the lifeworlds and needs of their staff, treat them with respect, and involve them in decisions affecting their work-life, then nurses are more likely to understand at a deeper level the significance of SBN, develop an SBN mind-set to guide their nursing of patients and families. Moreover, when the unit culture is strengths-based and when structures, tools, and resources are put in place, then PFCC through SBN will no longer be just rhetoric.

In September 2015, two of Canada's three Federal Granting Agencies - namely, the Social Science and Humanities Research Council and the Canadian Institute of Health Research - announced a one-time only initiative dedicated to Healthy Productive Work. We invited eight partners from five disciplines (nursing, management, oral history, sociology, and visual anthropology), four universities, and two hospitals to be co-applicants on a grant to develop and mount a training program for clinical managers and leaders in strengths-based leadership and management using innovative forms of story sharing that we would develop. The idea for this initiative had begun 18 months earlier under the auspices of the International Institute of Strengths-Based Nursing and Health Care (www.sbnhc.org).

We chose Hospital for Sick Kids (HSK), a quaternary care hospital, and Holland Bloorview Children's Rehabilitation Hospital (HB), Toronto, Canada, because they were early adopters of SBN and their institutional values aligned with SBN. Moreover, we had buy-in from their leaders, senior and middle management nursing teams, point-of-care nurses, and families.

The first step in developing the curriculum for the managers and clinical leaders' training program was to consult with unit managers to determine the knowledge and skills they wanted to develop and learn more about. In addition, a survey of clinical leaders from HSK and HB was undertaken to assess their learning needs and interest in understanding SBN, as well as the management/leadership concepts and skills that could be offered in a formal SBN management and leadership training program. Clinical leaders expressed a clear desire for such a program to help them in their role of implementing SBN.

We also understood that transforming the educational system and the workplace needed to happen concurrently. Yet each involves creating different plans that require different knowledge and skills. For example, in developing the training program for managers we needed the knowledge, experience, and skills of management operation systems. We also wanted to develop a new methodology to help develop the "art" of management that would develop sensitivity, imagination, flexibility, creativity, and encourage innovation and resourcefulness. We decided to use stories and story-sharing as our primary pedagogical approach. We believe that by using story-sharing, nurses will explore aspects of their personal life and their work worlds that that are imbued with meaning and how these meanings affect their nursing. To this end, we invited experts from oral history, sociology, and visual anthropology to be our partners to develop the materials for this course. 
Another component of the training program is to assign each participant a mentor for 6 months who will help them deal with real-life situations as they arise. It is our hope that this will increase the likelihood of change and sustainability. The SBN management and leadership training program will be piloted and evaluated.

Authentic interdisciplinary work involves collaborative partnership, a melding of knowledge, skills, and expertise. Our modus operandi has been one of co-designing and sharing ownership. Co-designing involves active engagement of all partners where together "you" and "yours" is replaced by "our" (Donetto, Pierri, Tsianakas, \& Robert, 2015). Through open and continuous communication, sharing purpose and communicating individual goals, we have begun to create common goals, with all partners buying into SB philosophy and its values. In fact, it was SB values that drove the process of shared ownership that facilitated the engagement and commitment of all partners of the project.

\section{Replacing Silos With Networks and Communities}

Ours is a world that is organized and operates in silos. A major shortcoming of silos is that systems, processes, and units operate in isolation, and such problems pervade health care (Hajek, 2013). Units in the health care system often fail to communicate with each other and understand each other's realities. This state of affairs characterizes the relationship between education and health care systems. The result is that they fail to act in synergy and do not benefit from each other's strengths, learn from each other's experiences, nor capitalize on each other's knowledge and expertise.

The gap between education and practice within and among professions has given rise to a whole industry dedicated to narrowing the gap (Jerlock, Falk, \& Severinsson, 2003). Yet for all the solutions advanced the gap remains and in many cases, has widened (Eggertson, 2013). By using the same SB values and foundational principles translated and tailored to practice (Gottlieb, 2014), education (Gottlieb \& Benner, 2013), and leadership/management (Gottlieb et al., 2012), we have found a way to create networks and communities dedicated to SB approaches that transcend silos and transport ideas, strategies, tools within and between systems, disciplines, and units.

\section{Facilitating Factors That Enable the Implementation Process}

There are many individual, organizational, and system factors that can help facilitate the implementation process. However, for this article, we have identified the most salient that we have found critical at this relatively early stage of adoption and implementation. These factors include values which align, a readiness to accept SBN, curiosity-courage-commitment of early adopters, a critical mass of champions and early adopters, and tailoring SBN by making it relevant and context specific. 


\section{Values Which Align}

Early adopters - individuals, units, or systems - have one thing in common: Their values align with many of the values of a SB approach. Even though they may not use SBN terminology, their actions are guided by many of the same SBN values. Thus it is not surprising that when they hear about SBN they can identify with it. They are drawn to SBN because SBN provides them with an articulated, comprehensive, and integrated philosophy, gives them tools and a language to communicate and make visible, what up until now they may have had difficulty articulating. Moreover, SBN enables them to operationalize their espoused values. For example, many organizations subscribe to Family Centered Care, yet their policies, procedures, institutional culture, and adopted behaviors belie their assertion. They are anything but family centered when they fail to allocate space for families to remain with their loved ones during a hospital stay, or when they do not make private space available for nurses to meet with families, or when they do not include families in planning care, making policy, and designing space.

\section{Readiness to accept SBN}

Early adopters also are aware that they or their institutions are ready for change. They are ready and prepared to move in a new direction. This process may have begun many years before with several strengths-based initiatives. They can see how SBN can help advance the unit or organization's mission statements and strategic plan. They are prepared to commit resources, energy, and people to its implementation.

\section{Curiosity, courage, commitment of early adopters}

To adopt a new philosophy begins with curiosity - a desire to learn more. Curiosity requires studying, listening, asking questions, being open to, genuinely interested in and engaging in dialogue and then deciding whether to move forward with SBN. To move forward also requires courage, to overcome fears, speak out, and present a different approach to the current way of practice. Commitment requires time, dealing with challenges and overcoming obstacles to enable this new approach to take root.

All early adopters shared these qualities. They formed book clubs to learn more, attended and organized workshops to expand and deepen their knowledge and understanding, translated ideas and related them to what they already were doing, had done, or had observed. Early adopters are by nature courageous. They use the gentle art of persuasion to get others to understand their perspective. They did so by sharing, organizing, communicating and by telling their stories, illustrating with concrete examples, making videos. Early adopters commit and persevere. They tackle obstacles by finding ways around them. Challenges are treated as opportunities. Their commitment is long-term not short-term as they know that it takes time to bring about significant and long-lasting change. 


\section{Critical mass of early adopters}

An SB approach requires a critical mass of individuals committed to its ideals. When a critical mass subscribes, adopts, and commits to SBN, it provides the momentum and lays the ground for more widespread adoption. Recall the group of Advanced Practice Oncology Nurses who attended a book club to learn more about SBN and then organized and met bi-monthly in reflective practice sessions. They began to see that they had come together as a Community of Practice of Advanced Practice Oncology Nurses dedicated to SBN. As their knowledge of SBN grew, they found themselves more comfortable in using SBN values to guide their nursing. They experienced the difference in their nursing, the difference they were having on their patients and families, and a difference in their own personal and professional development. After a year of meeting and discussing their nursing, they were ready to present SBN to the wider nursing community at a Nursing Ground Rounds. They were buoyed by the enthusiastic reception of their presentation and immediately scheduled to repeat Nursing Ground Rounds to those who could not attend and to take their presentation to other hospitals in their community. They presented at both national and international nursing and multidisciplinary conferences. Other groups within the oncology division and elsewhere in the hospital have come forward wanting to learn more about SBN and how to change the culture and practices within their units. From a core group, their circle of influence is widening as more nurses and nursing leaders join the SBN movement.

\section{Making an SB approach relevant and context specific}

An SB approach is a flexible, open philosophy that is relevant in all situations. As long as the basic principles of SB are honored, an SB approach is designed to assume different forms defined by the unique needs and characteristics of the specific context and setting. This explains in part how an SB approach has been developed among disparate disciplines such as psychology, economics, law, and counseling. The generic foundations of a strengths approach are empowerment, partnership, and relationships yet they can be interpreted differently and assume different forms depending on the context and purpose. For example, at HB Nursing Department adopted SBN as their nursing philosophy. They found within this approach that they could contribute to their hospitals' vision using a strength-based rehabilitation nursing model that could guide teaching and research. Dr. Marilyn Ballantyne, HB's Chief Nursing Executive/Clinical Investigator finds that StrengthsBased Care can help her nursing department achieve the hospital's vision " ... to empower clients and families to advocate for themselves in order to enhance every aspect of a child's potential, and to enable ourselves, our teams and our clients to achieve full impact through integrated best practices in care, research and learning." 


\section{Conclusion}

While there are a multitude of nursing philosophies, theories, and models, their implementation into the workplace has been difficult to achieve. A possible reason may be that the emphasis has been more on knowledge dissemination and specific knowledge transfer rather than on implementation whose goal is to change the practice of a profession. In the case of SBN, we have developed a process for implementation that is both multi-layered and multipronged approach. One of its key features is the development of a re-training program for clinical managers in Strengths-Based leadership and management. We focus on middle management (that is, those responsible for direct supervision of point-of-care nurses) because it is within their power to enhance the work environment of nurses and to create a culture that values compassionate, knowledgeable, strengths-based, familycentered care. We are involving many stakeholders in the process of implementation such as patients and families, clinicians, educators, leaders, managers, researchers, unions, opinion leaders, and policy makers from both nursing and other disciplines which involve both the educational and workplace sectors. It is when these stakeholders join forces, act in synergy, mobilize, and capitalize on each other's strengths will there be change - real change, profound change, lasting change - which will be reflected in nurses reclaiming the essence of nursing and patients, families, and communities living healthier, more productive, and meaningful lives.

\section{Acknowledgments}

We are indebted to Keith Adamson, Marilyn Ballantyne, Andrea Baumann, Bessy Bitzas, Antoinette Ehrler, Val Frunchuk, Steven High, Pam Hubley, Gretchen Keller Jenette Schoon, Vedat Verter for their invaluable contributions.

Declaration of Conflicting Interests

The author(s) declared no potential conflicts of interest with respect to the research, authorship, and/or publication of this article.

\section{Funding}

The author(s) disclosed receipt of the following financial support for the research, authorship, and/or publication of this article: The Strengths-Based Leadership Training Program and Story-Sharing is being funded by the Canadian Institutes of Health Research (ClHR) and Social Sciences and Humanities Research Council of Canada (SSHRC) through their co-sponsored funding opportunity, the Healthy and Productive Work Partnership Development Grant, which is part of the Healthy and Productive Work Initiative (http://www.cihr-irsc.gc.ca/e/47706.html) Ref\# 8902016-3054.

\section{References}

Agency for Healthcare Research Policy. (2006). National healthcare quality report. Rockville, MD: Agency for Healthcare Research and Quality. Retrieved from https://archive.ahrq.gov/qual/nhqr06/nhqr06report.pdf 
Berwick, D. M. (2003). Disseminating innovations in health care. Journal of the American Medical Association, 289, 1969-1975. doi:10.1001/jama.289.15.1969

Berwick, D. M. (2016). Era 3 for medicine and healthcare. Journal of the American Medical Association, 315, 1329-1330. doi: 10.1001/jama.2016.1509

Best, A., Hiatt, R., \& Norman, C. D. (2008). Knowledge integration: Conceptualizing communications in cancer control systems. Patient Education \& Counseling, 71, 319-327. doi: 10.1016/j.pec.2008.02.013

Birken, S. A., Lee, S.-Y. D., \& Weiner, B. J. (2012). Uncovering middle managers' role in healthcare innovation implementation. Implementation Science, 7, 28. doi: 10.1186/1748-5908-7-28

Caldwell, D. W., Chatman, J., O'Reilly, C. A., III, Ormiston, M., \& Lapiz, M. (2008). Implementing strategic change in a health care system: The importance of leadership and change readiness. Health Care Management Reviews, 33, 124133.

Cannan, K. L., Dardess, P., Maurer, M., Sofaer, S., Adams, K., Bechtel, C., \& Sweeney, J. (2013). Patient and family engagement: A framework for understanding the elements and developing interventions and policies. Health Affairs, 32,223-231. doi: 10.1377/hlthaff.2012.1133

Carter, M. R., \& Barrett, C. B. (2006). The economics of poverty traps and persistent poverty: An asset-based approach. Journal of Developmental Studies, 42, 178- 199. doi: 10.1080/00220380500405261

Chokshi, D. A., Chang, J. E., \& Wilson, R. M. (2016). Health reform and the changing safety net in the United States. New England Journal of Medicine, 375, 1790-1796. doi: 10.1056/NEJMhpr1608578

Cockburn, J. T., Thomas, F. N., \& Cockburn, O. J. (1997). Solution-focused therapy and psychosocial adjustment to orthopedic rehabilitation in a work hardening program. Journal Occupational Rehabilitation, 7, 97-106. doi: 10.1007/BF02765880

Dearing, J. W., Beacom, A. M., Chamberlain, S. A., Meng, J., Berta, W. B., Keefe, J.

M., ... Eastabrooks, C. A. (2017). Pathways for best practice diffusion: The structure of informal relationships in Canada's long-term care sector. Implementation Science, 12 (11), 1-13.

Donetto, S., Pieni, P., Tsianakas, Y., \& Robert, G. (2015). Experience-based codesign and healthcare improvement: Realizing participatory design in the public sector. The Design Journal, 18, 227-248.

Easterbrooks, C. A., Thompson, D. S., Lovely, J. E., \& Hofmeyer, A. (2006). A guide to knowledge translation theory. Journal of Continuing Education in Health Professions, 26, 25-36.

Eggertson, L. (2013). The gap between clinical practice and education. Canadian Nurse, 109, 22-26.

Feeley, N., \& Gottlieb, L. N. (2000). Nursing approaches for working with family strengths and resources. Journal of Family Nursing, 6, 9-24. doi: $10.1177 / 107484070000600102$

Gibson, C. H. (1991). A concept analysis of empowerment. Journal of Advanced Nursing, 16, 354-361.

Gooding, J. S., Cooper, L. G., Blaine, A. I., Franck, L. S., Howse, J. L., \& Berns, S. D. (2011). Family support and family-centered care in the neonatal intensive care unit: Origins, advances, impact. Seminars in Perinatology, 35, 20-28. doi: 10.1053/j.semperi.2010.10.004 
Gottlieb, L. N. (2013). Strengths-based nursing care: Health and healing for person and family. New York, NY: Springer.

Gottlieb, L. N. (2014). CE: Strengths-based nursing. American Journal of Nursing, 114, 24-32. doi: 10.1097/01.NAJ.0000453039.70629.e2

Gottlieb, L. N., \& Benner, P. (2013, November). Strengths-based nursing: Moving beyond deficits in nursing practice and nursing education. Educating Nurses Newsletter. Available from www.educatingnurses.com

Gottlieb, L. N., \& Feeley, N. (with Dalton, C.). (2005). The collaborative partnership approach to care: A delicate balance. Toronto, Ontario: Elsevier Canada.

Gottlieb, L. N., Gottlieb, B., \& Shamian, J. (2012). Principles of strengths-based nursing leadership for strengths-based nursing care: A new paradigm for nursing and healthcare for the 21st century. Journal of Nursing Leadership, 25, 38-50.

Gottlieb, L. N., \& Ponzoni, N. (2016). Canada: Strengths-based nursing. a value driven approach to practice. In J. J. Fitzpatrick \& A. L. Whall (Eds.), Conceptual models of nursing: Global perspectives (5th ed. pp. 44-59). New York, NY: Pearson.

Gottlieb, L. N., \& Rowat, K. (1987). McGill model of nursing: A practice-derived model. Advances in Nursing Science. 9, 51-61. doi:10.1097/00012272198707000-00008

Green, L. W., Ottoson, J. M., Garcia, c., \& Hiatt, R. A. (2009). Diffusion theory and knowledge dissemination, utilization, and integration in public health. Annual Reviews of Public Health, 30, 151-174.

Griffiths, P., Ball, J., Murrells, T., Jones, S., \& Rafferty, A. M. (2016). Registered nurse, healthcare support worker, medical staffing levels and mortality in English hospital trusts: A cross-sectional study. British Medical Journal Open, 6, e008751. doi: 10.1136/bmjopen-2015-008751

Gustafsson, C., Asp, M., \& Fagerberg, I. (2007). Reflective practice in nursing care: Embedded assumptions in qualitative studies. International Journal of Nursing Practice, 13,151-160.

Hajek, A. M. (2013). Breaking down clinical silos in healthcare. Frontiers of Health Services Management, 29. 45-50.

Hughes, K.-A., Carryer, J. B., \& White, J. (2015). Structural positioning of nurse leaders and empowerment. Journal of Clinical Nursing, 24, 2125-2132.

doi: 10.1111/jocn.12839

lacobucci, G. (2017). A service under pressure. British Medical Journal, 356, i6691. doi:10.1136/bmj.i6691

International Family Nursing Association. (2015). IFNA position statement on generalist competencies for family nursing practice. Retrieved from http:// internationalfamilynursing.org/wordpress/wp-content/uploads/2015/07/ GC-Complete-PDF-document-in-color-with-photos-English-language.pdf

Jacob, K. S. (2015). Recovery model of mental illness: A complementary approach to psychiatric care. Indian Journal of Psychological Medicine, 37, 117-119. doi: 10.4103/0253-7176.155605

Jerlock, M., Falk, K., \& Severinsson, E. (2003). Academic nursing education guidelines: Tool for bridging the gap between theory, research and practice. Nursing and Health Sciences, 5, 219-228.

Kitson, A., Conroy, T., Wengstrom, Y., Profetto-McGrath, J., \& Robertson-Malt, S. (2010). Defining the fundamentals of care. International Journal of Nursing 
Practice, 16, 423-434.

Koloroutis, M. (2004). Relationship-based care: A model for transforming practice. Minneapolis, MN: Creative Health Care Management.

Kooienga, S., \& Wilkinson, J. (2017). RN prescribing: An expanded role for nursing. Nursing Forum, 52, 3-11. doi:10.1111/nuf.12159

Kutney-Lee, A., Wu, E. S., Sloane, D. M., \& Aiken, L. J. (2013). Changes in hospital nurse work environments and nurse job outcomes: An analysis of panel data. International Journal of Nursing Studies, 50, 195-201. doi: 10.1016/j. ijnmstu.2012.07.014

Lang, E. S., Wyer, P. C., \& Haynes, R. B. (2007). Knowledge translation: Closing the evidence-to practice gap. Annals of Emergency Medicine, 49, 355-363.

Manary, M. P., Boulding, W., Staelin, R., \& Glickman, S. W. (2013). The patient experience and health outcomes. New England Journal of Medicine, 368, 201203. doi:10.1056/NEJMp1211775

Mintzberg, H. (2012). Managing the myths of health care. World Hospitals and Health Services, 48, 4-7.

Morgan, S., \& Yoder, L. H. (2012). A concept analysis of person-centered care. Journal of Holistic Nursing, 30, 6-15. doi:10.1177/0898010111412189

Mukamel, D. B., Haeder, S. F., \& Weimer, D. L. (2014). Top-down and bottom-up approaches to health care quality: The impacts of regulation and report cards. Annual Reviews of Public Health, 35, 477-497. doi:10.1146/annurev-publhealth-082313-115826

The National Academies of Sciences, Engineering, Medicine. (2010). The future of nursing: change, advancing health. Retrieved from

http://www.nationalacademies.org/hmd/Reports/2010/The-Future-of-NursingLeading-Change-Advancing-Health.aspx

Naylor, D., Fraser, N., Girard, F., Jenkins, T., Mintz, J., \& Power, C. (2015).

Unleashing innovation: Excellent healthcare for Canada (Report of the advisory panel on healthcare innovation). Ottawa, Ontario: Health Canada. Retrieved from http://healthycanadians.gc.ca/publications/health-system-systemesante/report-healthcare-innovation-rapport-soins/alt/report-healthcareinnovation-rapport-soins-eng.pdf

Nightingale, F. (1860). Notes on nursing: What it is and what it is not. London, England: Harrrison.

Northridge, M. E., \& Metcalf, S. S. (2016). Enhancing implementation science by applying best principles of system science. Health Research Policy Systems, 14, 74. doi: 10.1186/s12961-016-0146-8

Nussbaum, M. (2011). Creating capabilities. Cambridge, MA: Harvard University Press.

Peckham, C. (2015, November 18). Medscape nurse salary report 2015. Retrieved from http://www.medscape.com/features/slideshow/public/nurse-salaryreport-2015

Perla, R. J., Bradbury, E., \& Gunther-Murphy, C. (2013). Large-scale improvement initiatives in healthcare: A scan of the literature. Journal of Healthcare Quality, 35,30-40.

Read, E. A., \& Laschinger, H. K. S. (2015). The influence of authentic leadership and empowerment on nurses' relational social capital, mental health, and job satisfaction over the first year of practice. Journal of Advanced Nursing, 71, 1611-1622. doi:10.1111/jan.12625 
Regan, L. C., \& Rodriquez, L. (2011). Nurse empowerment from a middlemanagement perspective: Nurse managers' and assistant nurse managers' workplace empowerment views. The Permanente Journal, 15, e101-e107.

Registered Nursing Association of Ontario. (2016). Mind the safety gap in health system transformation: Reclaiming the role of the RN. Retrieved from RNAO. $\mathrm{ca} /$ mindthesafetygap_

Rodwell, C. M. (1996). An analysis of the concept of empowerment. Journal of Advanced Nursing, 23, 305-313.

Rogers, E. M. (2003). Diffusion of Innovations (5th ed.). New York, NY: Free Press.

Seligman, M. E., \& Csikszentmihalyi, M. (2000). Positive psychology: An introduction. American Psychologist, 55, 5-14. doi:10.1037/0003-066X.55.1.5

Sen, A. (1999). Development is freedom. New York, NY: Knopf.

Shariff, N. (2014). Factors that act as facilitators and barriers to nurse leaders' participation in health policy development. British Medical Council Nursing, 41, 20. doi: 10.1186/1472-6955-13-20

Shaw, E. K ., Howard, J., West, D. R., Crabtree, B. F., Nease, D. E., Jr., Tutt, B., \& Nutting, P. A. (2012). The role of the champion in primary care change efforts. Journal of the American Board of Family Medicine, 25, 676-685. doi: 10.3122/ jabfm.2012.05.110281

Suh, H. A. (Ed.). (2005). Leonardo's notebooks: Writing and art the great master. New York, NY: Black Dog and Leventhal Publishers.

Thornton, L. (2005). The model of whole-person caring: Creating and sustaining a healing environment. Holistic Nursing Practice, 19, 106-115.

Tomey, M. A. (2008). Nursing leadership and management effects work environments. Journal of Nursing Management, 17, 15-25.

Tornabeni, J., \& Miller, J. F. (2008). The power of partnership to shape the future of nursing: The evolution of the clinical nurse leader. Journal of Nursing Management, 16, 608-613.

Wallach, A. (2017, January 3). How to think like a futurist. Ideas TED. Retrieved from http://ideas.ted.com/three-ways-to-think-about-the-future/

\section{Author Biographies}

Laurie N. Gottlieb, RN, PhD, PhD (Hon), FCAHS, is a professor at the Ingram School of Nursing, McGill University, Montreal, Quebec, Canada, where she holds the Flora Madeline Shaw Chair of Nursing. She is also the Nurse-Scholar-in Residence at the Jewish General Hospital in Montreal and a co-director of the International Institute of Strengths-Based Nursing and Health Care. She has been a major proponent of family nursing for over 40 years during which she has taught and researched from a family perspective. Her earlier research focused on young family development during normative and non-normative events. Her current research focuses on the development of a training program for middle managers in Strengths-Based Leadership using innovative forms of story sharing to change the workplace environment for nurses to practice Strengths-Based Nursing. She is continuing to develop the underlying tenets of Strengths-Based Nursing including innate capacities for health and healing. She is developing materials and tools to guide practitioners, educators, leaders/managers, and researchers in using a strengths-based approach. Her recent publications include Strengths-Based Nursing Care: Health and Healing for Person and Family (2013), "Strengths-Based Nursing" in American Journal of Nursing (2012), and "Principles of Strengths- 
Based Nursing Leadership for Strengths-Based Nursing Care: A New Paradigm for Nursing and Healthcare for the 21st Century Journal of Nursing Leadership (2012, with B. Gottlieb, \& J. Shamian).

Bruce Gottlieb, PhD, is a project director at the Lady Davis Institute of Medical Research, Jewish General Hospital, an adjunct professor at the Ingram School of Nursing, McGill University, and an associate member of the Department of Human Genetics, McGill University. He is a co-founder of the International Institute of Strengths-Based Nursing and Healthcare. He is a geneticist whose current interests are in the genetics of cancer ontology and the role of tissue microenvironment factors in breast cancer. In addition, he is interested in the innate healing mechanisms that play a crucial but little understood or appreciated role in the healing process and how they are affected by both external and internal environments. His recent publications include "Principles of StrengthsBased Nursing Leadership for Strengths-Based Nursing Care: A New Paradigm for Nursing and Healthcare for the 21st Century" in Journal of Nursing Leadership. (2012, with L. N. Gottlieb \& J. Shamian) and "Changing Genetic Paradigms: Creating Next-Generation Genetic Databases as Tools to Understand the Emerging Complexities of Genotype/Phenotype Relationships" in Human Genomics (2014, with L. K. Beitel, \& M. Trifiro). 